\title{
Emphasis on Photovoltaic (PV) Solar System Installation training: A case study of a PV Solar System Installed in Makueni County, Kenya
}

\author{
Sebastian Waita ${ }^{1}$, Bernard Aduda ${ }^{2}$ \\ Department of Physics, University of Nairobi, Nairobi, Kenya ${ }^{1,2}$
}

\begin{abstract}
The installation of Photovoltaic (PV) solar systems in institutions as well as homesteads in the rural areas in Kenya is increasing at a high rate; and so is the need for the stake holders to make sure the PV solar systems are professionally designed, sized, installed and maintained. In PV solar system installation, the designing, sizing and the installation are very critical steps. A wrongly designed, sized and installed system will not perform optimally and will underperform (for undersized systems) and waste energy and resources (for oversized systems). Furthermore, undersized systems do not perform to the user's expectation discouraging the user and eventually a negative customer attitude creeps in which may affect the uptake of solar PV systems. On the other hand, an oversized PV system is extra expense on the side of the client, creating an exaggerated high cost of PV solar systems, again discouraging potential clients from the adoption of the technology. Both scenarios mean loss of business, jobs and the economic and social benefits associated with PV technology. We present a case study of poorly installed PV systemsin Makueni County, Kenya. We observed that the solar modules specifications at the back of the modules were not clearly done, the batteries were poorly matched and the cables used in the installation were undersized. Due to these issues, even a normal television set was not able to work since the system was installed four years ago (in 2012).The above case emphasizes the need for training in PV solar system design, sizing, installation, and maintenance.
\end{abstract}

Key words: Photovoltaic (PV), modules, solar system, Installation, training, professional

\section{INTRODUCTION}

The World Bank estimates that there are over 2 billion In the last decade alone, annual sales of PV systems have people all over the world who do not have grid topped $15 \%$, mostly SHS, taking $75 \%$ of the sales.

electricity[1] Most of these people live in scattered According to Kenya Renewable Energy Association homesteads in developing countries where electric grid (KEREA), asat 2008, over 200,000 PV systems had been connection would be very expensive and therefore un installed in Kenya but the increasing number of untrained economical. In such a scenario, Solar Home systems freelance solar installers was of concern [8].A total of 75 (SHS) comprising one or a few solar modules (panels) PV systems across the country were surveyed by KEREA offer a suitable solution. In Kenya, about $75 \%$ (35 and the main findings were: lack of labels in equipment or million) ofthe people had no grid electricity as at 2012.

Most of the energy needs for the population is met using solid Biomas for their energy needs [2].In 2011, Kenya had an installed capacity of $1590 \mathrm{Mw}$, increasing to 1773 Mw by May, 2014. The electricity peak demand is expected to increase annually and is estimated to be 2,511 Mw by 2015 and $15,026 \mathrm{Mw}$ by 2030 [3].

In order to meet this energy demand a multi energy generation approach is required. Although Kenya has great potential for renewable energy [4-6], only $3 \%$ is generated from renewables. The government, in its' strategic plan had planned togenerate $10 \mathrm{Mw}$ of solar power by 2015 as part of its' target of $30 \mathrm{Mw}$ from renewables by 2018 [7]. However, so far, only 1,000 public institutions across the country, mainly in off gird areas have been installed with solar PV systems amounting to $2 \mathrm{Mw}$. The annual PV market is estimated at $500 \mathrm{~kW}$ and is expected to grow at $15 \%$ annually[3, 7]. illegible labels, undersized connecting cables, untidy wiring, wrong battery positioning, no charge controller connected or charge controller by passed, use of automotive batteries instead of solar batteries, wiremesh covered modules (for security reasons), cases of users installing themselves due to un availability of an installer, cases of mechanics, radio repairers, grid electrical installators or general artisan with no training in PV installation doing the installation [9].

The solar system would then either fail to work or work for a while and stop functioning. The large number of untrained solar installers led to poor system installations leading to a low opinion to solar power as an alternative energy solution. This prompted the Kenya Renewable Energy Association (KEREA) to initiate a training Programme for PV solar installers [8].

In this work, we present a case study of a poorly installed PV system. We also provide an illustration of a PV system 
installed after the installer has gone through a solar PV Installation training course. The contrast emphasizes the need for solar installers to be trained.

\section{THE MAIN COMPONENTS OF AN OFF-GRID SOLAR PV SYSTEM}

An off grid photovoltaic solar system has a number of key components namely:

1. The solar modules/Panels

2. The inverter

3. The Battery bank

4. The charge controller

5. The cables and other accessories

6 . The load

\section{DETAILS OF THE SOLAR PVSYSTEM INSTALLATION}

The solar PV system was installed in 2012 but the user claimed that it has never provided the desired service. We traced the reason to inadequate charging current from the modules leading to low battery bank storage and hence dead batteries as discussed below.

\subsection{The Lighting}

Observation: The Installation had twenty lights with a total Wattsof $350 \mathrm{~W}$. Some lighting points had $45 \mathrm{~W}$ bulbs and the lowest rated bulb was $12 \mathrm{~W}$.

Comment: The lights used in the system had un necessarily high rating which increased the system cost. The installer should have guided the client on the use of energy saving bulbs or even light emitting diode (LED) lights to save on cost.

\subsection{The PV modules}

Observation: There were two modules of $80 \mathrm{~W}$, here designated as Module 1 and 2 . The modules were tightly fixed on to the iron roof top as shown in figure 1 (a) below.

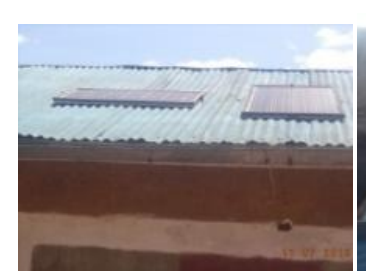

21

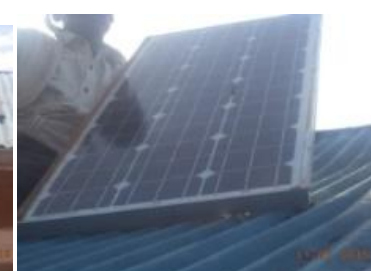

(b)
Table 1.Module specifications as read directly from the back of the modules

\begin{tabular}{|l|l|l|l|}
\hline Parameter & $\begin{array}{l}\text { Module } \\
1\end{array}$ & Parameter & $\begin{array}{l}\text { Module } \\
2\end{array}$ \\
\hline \multicolumn{2}{|l|}{$\begin{array}{l}\text { Company name } \\
\text { withheld }\end{array}$} & $\begin{array}{l}\text { Company name } \\
\text { withheld }\end{array}$ \\
\hline Power & $80 \mathrm{~W}$ & Power & $80 \mathrm{~W}$ \\
\hline $\mathrm{I}_{\mathrm{m}}$ & $21.6 \mathrm{~V}$ & $\mathrm{I}_{\mathrm{m}}$ & $\begin{array}{l}\mathrm{I}_{\text {input }}, \\
4.568 \mathrm{~A}\end{array}$ \\
\hline $\mathrm{V}_{\mathrm{m}}$ & $4.5 \mathrm{~A}$ & $\mathrm{~V}_{\mathrm{m}}$ & $17.6 \mathrm{~V}$ \\
\hline $\begin{array}{l}\text { Short circui } \\
\text { voltage }\end{array}$ & $3.48 \mathrm{~A}$ & $\begin{array}{l}\text { Short } \\
\text { circuit } \\
\text { current }\end{array}$ & $5.12 \mathrm{~A}$ \\
\hline $\mathrm{V}_{\mathrm{oc}}$ & $\begin{array}{l}\text { Faded, } \\
\text { Illegible }\end{array}$ & $\mathrm{V}_{\mathrm{oc}}$ & $21 \mathrm{~V}$ \\
\hline
\end{tabular}

Comment: Looking at the parameters in table 1 above, one maybe forgiven for thinking that it was the mistake of those taking the data, but not at all. The information was read severally to be sure. As can be seen,for module 1 , the current at the maximum power point, $I_{m}$ is given in volts while the Voltage at maximum power point, $V_{m}$ is in Amperes. The open circuit voltage, $V_{o c}$ could not be legible. These may not just be errors or oversights from the manufacturer, but most likely the work of a person who doesn't understand the meaning of these parameters. This view is strengthened by the fact that the label was just loosely stuck at the back of the module and easily accessible. This printing of labels as we can call it,gives a false impression of the module parameters and is misleading to the client.

The parameters in Module 2 were professionally done. Measurements done on a sunny afternoon gave values of module voltage/current at the charge controller terminals as $13.3 \mathrm{~V} / 0.75 \mathrm{~A}$ and $20.6 \mathrm{~V} / 0.75 \mathrm{~A}$ for module 1 and 2 respectively. A low charging current was observed from the modules, which was not expected from such rated modules and on a sunny day. There was a possible current leakage or loss from the $1.5 \mathrm{~mm}^{2}$ cables used to connect the charge controller to the modules. The modules were firmly fixed in total contact with the iron roof leaving no space for air circulation to enhance the cooling of the modules. A well installed module should be a few centimeters off the roof to allow for air circulation so that the module temperature does not rise too high. Power generation is depended on the module temperature, as the open circuit voltage drops with module temperature increase [10].

\subsection{The Charge controllers}

Fig 1.Photos of the installation before training on solar PV installation. The modules as installed: (a) Left Module 1,

Right module 2 (b) A solar PV technician reading the module specifications

Themodules specifications as it appeared at the back (figure 1 (b) above) of the modules were as follows:
Observation: The solar system had two charge controllers: 15A (Amperes) and $10 \mathrm{~A}$ (Amperes) (see figure2 (a) below). Both charge controllers were connected to the modules using $1.5 \mathrm{~mm}^{2}$ Cables. The wires around the charge controllers looked untidy. 
Comment: It was not easy to access the charge controllers. Charge controllers should easily be accessible. The cables connectingthe charge controllers to the modules were $1.5 \mathrm{~mm}^{2}$ which is smaller than the recommended minimum size of $2.5 \mathrm{~mm}^{2}$ for the worst case scenario. This could increase the power loss in the system through increased voltage drop. Connecting wires should be neatly arranged in the system.

\subsection{The Batteries}

Observation: There were four flooded type batteries: Two rated $50 \mathrm{Ahrs}$ (Ampere hours) each and one rated80 Ahrs and another 100 Ahrs. The 50 Ahrs batteries were connected in parallel and the 80 Ahrs and the 100 Ahrs were also connected in parallel. The two parallel sets were then connected together in series. The batteries where connected using $1.5 \mathrm{~mm}^{2}$ cables across the positiveterminals and $4 \mathrm{~mm}^{2}$ acrossthe negative terminals. The 50 Ahrs batteries were connected to one charge controller and the 80 and $100 \mathrm{Ahr}$ connected to the other charge controller.Both connections to the charge controllers were done using two parallel joined $1.5 \mathrm{~mm}^{2}$ cables. The batteries were confined in the corridor shown below in figure2 (b). There was an Un interruptible Power Supply (UPS) device connected to the batteries.

Comment: It is not a good practice toconnect twodifferently rated batteries (the $80 \mathrm{Ahrs}$ and the 100 Ahrs) as this wastes part of the energy for the higher rated battery since the lower rated battery determines the energy supply from the batteries. The cable sizes interconnecting the batteries were also undersized and would waste energy. Batteries should be positioned in a well-ventilated place with adequate air circulation.

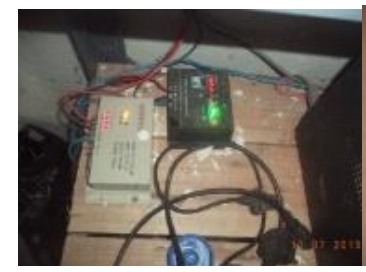

(a)

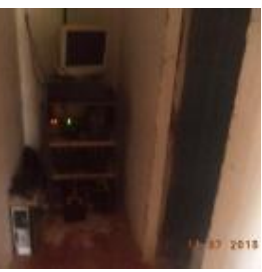

(b)
Fig 2.Photos of the installation before training on solar PV installation. (a) the charge controllers and wires around it (b) the batteries and charge controllers rack.

\section{INSTALLATION AFTER GOING THROUGH SOLAR PV INSTALLATION TRAINING}

The installer went through training in solar system installation and maintenance in the Physics Department, University of Nairobi.The installer was trained on importance of using quality products by ensuring purchases from reputable dealers to minimize chances of counterfeits and to always confirm the ratings especially on the modules by doing some basic tests where the situation allows. In figure 3 , is a display of two different solar systems installed after the training. Figure3 (a) is a re-installation of the system described above and for the first time, the client watched television after the installation. All the lights were also powered by solar and they worked very well.

The client was advised on using LED lights which gave adequate lighting while consuming little power. A total of 15 lights were replaced. Figure 3 (b)-(d) is another system the trainee went to install elsewhere.

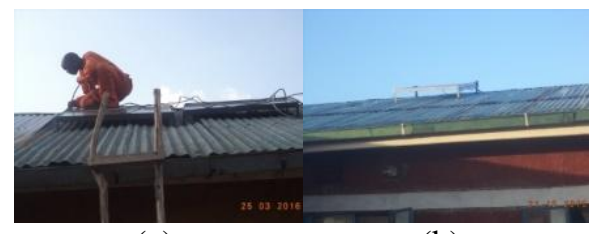

(a)

(b)

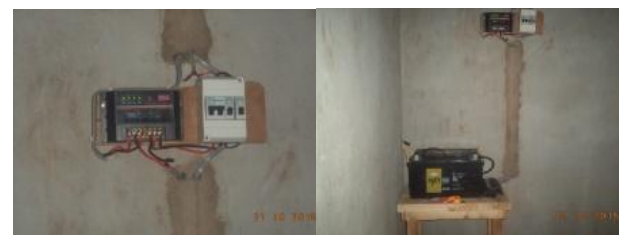

(c)

(d)

Fig 3.Photos of the installation after training on solar PV installation. (a) Re-installation of the system described above (b) module installed in another project (c) the wire arrangement at the controller area (d) the battery on its rack.

As seen in figure3 (a) and (b), the modules havea good roof- module clearance enabling cooling through air circulation (compare with figure 1 (a)). Figure 3 (c) and (d) indicates a well wired charge controller with cables neatly in place as opposed to the situation in figure 2 (a). With training on positioning of batteries in a wellventilated place and its positioning with respect to the charge controller, figure 3 (d) shows exactly that.

Data taken after installation showed that the battery voltage was $13.2 \mathrm{~V}$ which was the same value at the load terminals of the charge controller. The voltage at the module-charge controller terminal was $18.3 \mathrm{~V}$. This system status indicated a well working system, confirmed through testing (switching on) of the lights.

\section{CONCLUSION}

A case study of a solar PV system installed by an un trained installer has been presented and shows lack of understanding of PV systems right from selection and purchase of the equipment's to the actual installation. This type of installation left an unsatisfied client.

On the other hand, after going through training on solar PV installation course, there is evidence of improved service provision and increased knowledge on PV systems. It is therefore paramount that PV installers be trained fully before handling any PV system assignments. 


\section{ACKNOWLEDGEMENT}

The author wishes to thank Abednego Kiwia and Jackson Nene for allowing the use of their installed solar PV systems as case studies. International Science Program (ISP) is thanked for facilitating training that resulted in this study.

\section{REFERENCES}

[1]. Geoff Stapleton, LalithGunaratne and Peter JM Konings, The Solar Entrepreneur's Hand book, $1^{\text {st }}$ Ed., Global Sustainable Energy Solutions Pty Ltd, NSW Australia, 2002, pp 113-115.

[2]. International Energy Agency (IEA)13-31, Africa Energy Outlook: A Focus on Energy Prospects in Sub-Saharan Africa, World Energy Outlook: A Special Report of International Energy Agency (IEA), 2014.

[3]. http://www.renewableenergy.go.ke, Accessed, $18^{\text {th }}$ Dec, 2015.

[4]. Kefa V.O. Rabah, "Integrated solar energy systems for rural electrification in Kenya",Renewable Energy,Vol. 30, Iss. 1, pp. 2342, January 2005.

[5]. Charles Nzila,Jo Dewulf,Henri Spanjers,Henry Kiriamiti and Herman van Langenhove, "Biowaste energy potential in Kenya”,Renewable Energy,Vol. 35, Iss. 12, pp. 2698-2704, December 2010.

[6]. J.K. Kiplagat, R.Z. Wang and T.X. Li, "Renewable energy in Kenya: Resource potential and status of exploitation", Renewable and Sustainable Energy Reviews,Vol. 15, Iss. 6, pp. 2960-2973, August 2011.

[7]. Economic Consulting Associates (ECA), Ramboll, 2-9, Technical $\&$ Economical Study for the Development of Small Scale Grid Connected Renewable Energy in Kenya, Kenya Small Scale Renewables,(2012).

[8]. KEREA Annual Report 5-12,Kenya Renewable Energy Association (KEREA), 2008.

[9]. KEREA Field Report, 6-25,Photovoltaic System field inspection and testing, Kenya Renewable Energy Association (KEREA), 2009.

[10] Peter Wurfel, Physics of Solar Cells: From Basic Priciples to Advanced Concepts, $2^{\text {nd }}$ Ed., Wiley-VchVerlag GmbH, 2009, pp 81. 